eISSN: 2387-1555

DOI: http://dx.doi.org/10.14201/rea202093343

\title{
MEMORIA HISTÓRICA EN TORNO AL USO DE LA TIERRA EN HUEJÚCAR Y TLALCOSAGUA A FINALES DEL PERIODO COLONIAL
}

\section{Historical memory in the use of land in Huejucar and Tlalcosagua at the end of the colonial period}

\author{
Memória histórica em relação ao uso de terra em Huejúcar e Tlalcosagua no final do perio- \\ do colonial
}

\author{
Paulina ULTRERAS VILLAGRANA \\ Universidad de Guadalajara, CUTonalá, México. \\ \paulina.ultreras@,ciesas.edu.mx \\ ORCID: https:/ / orcid.org/0000-0003-4459-216X
}

Fecha de recepción: 18 de septiembre de 2019

Fecha de aceptación: 4 de enero de 2020

\begin{abstract}
Resumen: La utilización de la memoria y el pasado de los indios colotlecos, en particular de los indígenas de Huejúcar y Tlalcosagua, serán analizados a través de un juicio seguido contra la hacienda La Quemada, en las últimas décadas del periodo colonial. El objetivo consiste en mostrar la construcción histórica en la adquisición de tierras para frenar el avance territorial de la hacienda La Quemada. Los indígenas de ambos pueblos pertenecían al gobierno de las Fronteras de Colotlán, lo que les otorgaba privilegios obtenidos desde 1591 con la creación del gobierno fronterizo y la llegada de familias tlaxcaltecas para pacificar y sedentarizar la zona. Los privilegios concedidos en 1591 se siguieron utilizando como recurso histórico hasta finales del periodo colonial. En este artículo analizo un juicio de tierras donde se enfrentan indígenas y hacendados, y estudio cuáles eran las bases para el acceso a la tierra de ambos actores.
\end{abstract}

Palabras clave: memoria histórica; colotlecos; tlaxcaltecas; hacienda.

\begin{abstract}
The use of the memory and the past of the colotlecos indians, in particular of the indigenous people of Huejúcar and Tlalcosagua, will be analyzed through a trial followed against the hacienda La Quemada, in the last decades of the colonial period. The objective is to show the historical construction in the acquisition of land to curb the territorial advance of La Quemada. The indigenous of both towns belonged to the government of the borders of Colotlán, which granted them privileges obtained since 1591 with the creation of the border government and the arrival of tlaxcaltecan families to pacify and sedentary the area. The privileges granted in 1591 continued to be used as a historical resource until the end of the colonial period. In this article I analyze a land trial where indigenous and landowners confronted each other, and I study what the bases for the access to land of both
\end{abstract} actors were.

Keywords: Historical memory; colotlecos; tlaxcaltecas; hacienda.

Resumo: O uso da memória e do passado dos índios colotlecos, em particular dos indígenas de Huejúcar e Tlalcosagua, será analisado por meio de um julgamento seguido contra a fazenda La Quemada, nas últimas décadas do período colonial. O objetivo é mostrar a construção histórica na aquisição de terrenos para impedir o avanço territorial da fazenda La Quemada. Os nativos de ambas as cidades pertenciam ao governo das fronteiras de Colotlán, que lhes concedeu privilégios obtidos desde 1591 com a criação do governo de fronteira e a chegada de famílias tlaxcaltecas para pacificar e sedentarizar a área. Os privilégios concedidos em 1591 continuaram sendo utilizados como recurso histórico até o final do período colonial. Neste artigo, eu analiso um juízo de terra em que indígenas e proprietários de terra se confrontam, e estudo quais foram as bases para o acesso à terra de ambos os atores.

Palavras chave: memória histórica; colotlecos; tlaxcaltecas; fazenda.

\section{Introducción}

El caso presentado en las siguientes páginas recupera el conflicto por tierras que siguieron los pueblos de Huejúcar y Tlalcosagua con la obra pía La Quemada. A través del proceso judicial veremos cómo se organiza la 
memoria histórica en torno a la defensa de sus tierras. Por una parte, se habla de los indígenas fieles al servicio de la Corona, y por otro lado, de indígenas como seres incivilizados, bárbaros y utilitaristas, dependiendo del fin a conseguir y de quiénes elaboran el discurso. Detrás de esas narraciones yace la agenda tanto de los pueblos indígenas como de los hacendados.

Para comprender cabalmente cómo se materializó la memoria histórica comenzaré por desarrollar algunos antecedentes sobre la formación del gobierno de las Fronteras de Colotlán, al que pertenecían los pueblos aquí referidos. Seguido de los privilegios que gozaron los tlaxcaltecas en la fundación de pueblos y la relevancia de ser indio fronterizo, sin importar su condición étnica, durante el periodo colonial. Después, continuaré con la formación de la hacienda La Quemada. El objetivo consiste en analizar cuáles eran las bases para el acceso a la tierra de ambos actores.

Los documentos que permitirán efectuar el análisis fueron encontrados en el Archivo de la Real Audiencia de la Nueva Galicia y el Archivo Histórico de Jalisco, sección Tierras y Aguas. Los testimonios recuperados toman en consideración la defensa presentada por ambas partes y rastrean la genealogía en la adquisición de tierras. La construcción histórica en la adquisición de bienes es el hilo conductor en la defensa de las partes involucradas, no obstante, aquí me centraré en la de los pueblos indígenas, pues el objetivo del trabajo es analizar un juicio de tierras donde se enfrentan indígenas y hacendados. Para lo cual, retomo otras fuentes primarias, como las visitas, pues permiten conocer las características de los pueblos indígenas, en particular la fundación de los mismos.

En la defensa presentada por los indígenas pondré particular atención en la decisión de unirse con otro pueblo para fortalecer su defensa, en subrayar la especial relación que mantenían con la Corona y en los documentos que generaron los indígenas para su defensa en donde manifiestan su versión de la dotación de tierras.

\section{Indios fronterizos}

El gobierno de las Fronteras de Colotlán fue creado en 1591 con la finalidad de reducir, no sólo coercitiva sino también espiritualmente a los «indios belicosos» que poblaban el septentrión novohispano allende el río Santiago. Después de una cruenta guerra (la guerra chichimeca) entre colonizadores e indígenas y con las fuerzas menguadas por parte de los europeos, la Corona española, en particular el virrey en turno, Don Luis de Velasco, decidió mandar poblar puntos estratégicos por familias tlaxcaltecas para contener a los chichimecas. La Corona tenía intereses económicos en la pacificación pues ya se habían descubierto las minas zacatecanas (1546-1548), pero la exploración y explotación de los yacimientos era difícil debido a la inseguridad en la región, el constante asalto a las caravanas europeas en la denominada ruta de la plata y la falta de estabilidad e infraestructura para la explotación de las minas. Sin embargo, anterior a la formación del gobierno fronterizo existieron políticas de pacificación que incluyeron la erección de presidios en lugares estratégicos, importantes en este contexto. Incluso, desde 1542 se fundaron pueblos con españoles en la región, tal es el caso de Tlaltenango, Colotlán, Santa María de los Ángeles y Huejúcar (GÜERECA, 2016: 59). Por lo que en las inmediaciones del gobierno fronterizo existieron pueblos de españoles, mientras que en Colotlán, una vez erigido el gobierno fronterizo, había barrios de españoles y de indígenas.

A las familias tlaxcaltecas que se asentaron en los sitios fronterizos se les repartió tierra y se les otorgaron ciertos privilegios con el fin de llevar buenas costumbres y lograr la pacificación plena de los chichimecas, la conversión a las nuevas formas religiosas y el desarrollo de la agricultura y la ganadería (FERNÁNDEZ y ROMÁN, 1999: 18). Los chichimecas eran, desde la perspectiva europea, un grupo de indígenas que incluían, 
en el área del gobierno de las Fronteras de Colotlán, huicholes, tepehuanes y coras. En cada poblado donde se asentaron familias tlaxcaltecas se formaron barrios o parcialidades. En Colotlán, en 1616, el oidor Juan Dávalos y Toledo aseguraba que dicho pueblo contaba con tres parcialidades: la de los tlaxcaltecas, los tochos y los chichimecos $^{1}$ (BERTHE, CALVO y JIMÉNEZ 2000: 338-345).

Los privilegios concedidos a los tlaxcaltecas por los servicios conferidos a la Corona incluían derecho a portar armas; ellos y sus descendientes se consideraban hidalgos y libres de cualquier impuesto, tributo y servicio personal a perpetuidad; derecho a montar caballo ensillado; usar freno; etcétera (SEGO, 1998: 265-266). Los indígenas del gobierno fronterizo, no solamente los descendientes de tlaxcaltecas, se convirtieron en indígenas al servicio de la Corona y formaron milicias de indios flecheros para conservar la paz, reprimir a otros indígenas y defender la frontera.

De acuerdo con Fray José Arlegui, los tlaxcaltecas, además de ser considerados «hijosdalgos de Castilla», debían gozar en sus pueblos de tres leguas por cada viento (ARLEGUI, 1851: 284). Desde 1604, según el informe de Mota y Escobar, las estancias de ganado mayor y tierras de agricultura de los españoles circundaban las tierras de los pueblos de indios (MOTA Y ESCOBAR, 1940: 133-135). Desde la perspectiva de Mota y Escobar, las tierras de Colotlán y Huejúcar eran muy fértiles por lo que estas heredades eran atractivas para los españoles quienes, además de dedicarse a la minería, adquirieron tierras para sembrar y tener ganado. Asimismo, tenemos noticia que desde 1616 los indígenas arrendaban sus tierras a españoles (BERTHE, CALVO y JIMÉNEZ, 2000: 338-345), ello suscitaba conflictos entre unos y otros por la falta del pago de la renta y la invasión de terrenos por parte de los europeos. Todavía en 1783 se informaba que los indígenas de esta región arrendaban sus tierras a los españoles (VELÁZQUEZ, 1961: 39), por lo que la práctica del arriendo se extendió durante el periodo colonial.

Sabemos, por las descripciones de los visitadores, que la agricultura y la ganadería en Colotlán y los pueblos colindantes eran imprescindibles pues abastecían las minas zacatecanas, asimismo, existía intenso comercio entre los pueblos y ciudades circundantes y se explotaban los recursos forestales, tanto la madera como la leña eran esenciales en la vida cotidiana y en las minas (ARREGUI, 1980: 156-157).

Con la llegada de los Borbones al trono una serie de reformas se llevaron a cabo en territorios americanos. En la Nueva España la reestructuración del territorio y la recaudación fiscal eran las principales tareas a emprender. El gobierno de las Fronteras de Colotlán no fue la excepción y se pidieron informes de la situación del gobierno con el objetivo de eliminarlo, quitar las prerrogativas a sus pobladores y exigir el pago de impuestos. Sin embargo, los colotlecos exigieron el respeto a los privilegios obtenidos en 1591, recordando a las autoridades su importancia para mantener la paz en los caminos y asegurar la protección de los europeos en su tránsito por el territorio. Asimismo, insistían en su importancia como indios flecheros a las órdenes de la Corona española. Las autoridades reconocían la necesidad de los indígenas en la defensa de la frontera, pero también advertían el peligro que representaban para la Corona si decidían utilizar sus armas contra las autoridades. Para controlarlos se ordenó la prohibición de llevar a cabo campañas militares a menos que fueran acompañados por un español (GÜERECA, 2016: 67). Los indígenas conservaron sus privilegios durante todo el periodo colonial, pero es importante señalar que la memoria histórica se convirtió en un recurso fundamental en la defensa de sus tierras.

${ }^{1}$ Desafortunadamente el texto no aporta más elementos que nos indiquen quiénes eran los tochos y los chichimecos. 


\section{La adquisición de tierras: los hacendados}

La hacienda La Quemada se ubicaba en la jurisdicción de Juchipila, su primer dueño fue Juan Francisco de Bárcena, vecino de la ciudad de Zacatecas, dedicado a la agricultura y cría de ganado mayor y menor en Jerez y Juchipila. En 1725 Bárcena incrementó su patrimonio con la compra de nueve sitios de ganado mayor, ${ }^{2}$ todos en el partido de Villa Gutierre del Águila, perteneciente a Juchipila. ${ }^{3}$

En 1733, después de la muerte de Juan Francisco Bárcena, el nuevo dueño fue su hijo, Juan Manuel de Bárcena, quien junto con su esposa Catalina Fernández de Castro, fundaron la Obra Pía con las haciendas La Quemada, Guacasco, Buenavista y El Cuidado. Los documentos encontrados en el Archivo de la Real Audiencia y en el Archivo Histórico de Jalisco 4 muestran que a medida que adquirían más propiedades, los Bárcena buscaban apoderarse de las tierras inmediatas a sus haciendas o ranchos, argumentando que se trataba de tierras realengas, aunque la documentación indica constantes litigios con los vecinos, generalmente indígenas, así surgió el conflicto con los pueblos de mi interés.

Jan Bazant (1980) demuestra que en aquellos lugares donde hubo pueblos indígenas formados por familias tlaxcaltecas, éstas defendieron con ahínco sus tierras ante la invasión de los hacendados. La hipótesis de Bazant es que las comunidades preservaron sus tierras porque poseían la cohesión de los tlaxcaltecas y aún en 1722 declaraban que como descendientes de tlaxcaltecas tenían privilegios provenientes de las capitulaciones 5 (BAZANT, 1980: 23-33).

Los conflictos entre la obra pía La Quemada y los pueblos indígenas se ubicaban en las tierras de la hacienda El Cuidado. Los abogados de los hacendados rastrearon los orígenes de la hacienda y lo remontaron a 1568, cuando se le otorgaron dos caballerías de tierra a Simón de Coca a dos leguas de Huejúcar. En 1571 a Alonso López le concedieron un sitio de estancia para ganado mayor y dos caballerías en el pueblo de Quabite. En 1668 el capitán Diego de la Torre presentó merced de un sitio de estancia para ganado mayor una legua río arriba de Huejúcar, con fecha de septiembre de 1590. El capitán mostró sus documentos para probar que poseía y tenía poblado el sitio porque a los naturales de Huejúcar se les había dado título, emitido por la Real Audiencia de Guadalajara, de una legua por cada viento, ${ }^{6}$ por lo que el capitán mandó medir sus tierras para obviar litigios y fue amparado en su posesión. ${ }^{7}$

El expediente referido incluso señala que los jacales con que tenía poblado el capitán de la Torre su sitio quedaron 200 varas fuera de la legua perteneciente a los indígenas, por lo que el alcalde mayor ratificó la posesión. En 1703 se midieron los terrenos de la hacienda y quedaron dentro de sus límites una cofradía y algunos ranchos que tenían arrendados los naturales de Tlalcosagua, señalando que los indígenas poseían un pueblo de media legua por cada viento, ${ }^{8}$ por lo que deduzco que el pueblo lindaba con los terrenos de la hacienda, de ahí la necesidad de señalar sus linderos. Las tierras arrendadas por los indígenas estaban en disputa y los hacendados indicaban ser los dueños.

\footnotetext{
${ }^{2}$ Un sitio de ganado mayor equivale a $17.56 \mathrm{~km}^{2}$ y una caballería de tierra a 42.8 hectáreas. Datos tomados de Jan Bazant (1980: 6).

${ }^{3}$ BPEJ, ARA, Ramo civil, caja 305, exp. 10, progresivo 4412.

${ }^{4}$ BPEJ, ARA, Ramo civil, caja 253, exp.1, progresivo 3377 y caja 295, exp. 20, progresivo 4181. AHJ, Libros de Gobierno, libro 50, fs. $42 \mathrm{f}-$ $45 \mathrm{f}$.

${ }^{5}$ En las capitulaciones otorgadas por el virrey Luis de Velasco a los tlaxcaltecas, se les dieron cinco leguas por cada viento en las que no se podía hacer merced de ganado.

${ }^{6}$ Un viento se refiere a un punto cardinal.

7 BPEJ, ARA, Ramo civil, Caja 173, exp. 2, progresivo 1932, 1788-1798, fs. 51f-52f.

${ }^{8}$ BPEJ, ARA, Ramo civil, Caja 173, exp. 2, progresivo 1932, 1788-1798, fs. 121v-123f.
} 


\section{La fabricación de títulos primordiales}

Los indígenas de Huejúcar, en los documentos sobre la fundación de su pueblo, rememoraban la expedición organizada por el virrey Luis de Velasco con familias tlaxcaltecas para poblar la gran chichimeca, de ahí la fundación de Huejúcar, para contener las invasiones de los chichimecas. Las medidas de los límites del pueblo fueron ejecutadas por Prudencio Pérez Negrón, por mandato de la Real Audiencia. ${ }^{9}$ Los de Huejúcar aseguraban que el pueblo se había fundado en 1562 (fecha anterior a la de Simón de Coca quien afirmaba haber obtenido merced de dos caballerías de tierra en 1568 a dos leguas de Huejúcar) y Tlalcosagua en 1577, y como su principal tarea fue la de «contener en sus términos a la bárbara nación de Nayarith y otras muchas de infieles, insolentes indios, se han hecho acreedores a las gracias y privilegios que en distintas ocasiones se les han concedido». ${ }^{10}$ Los habitantes de Huejúcar mostraron título expedido por el virrey Gaspar de Zúñiga el 20 de noviembre de 1562 en el cual les concedía 226 cordeles por cada viento, esto es dos leguas. ${ }^{11}$

La fundación de Tlalcosagua tuvo lugar porque un grupo de indígenas que originalmente pertenecían a Huejúcar se establecieron en un punto denominado «quiohtrilo», ubicado a dos leguas y media de Huejúcar, por lo que se constituyó como barrio de Huejúcar en el cual se dedicaban a la agricultura aprovechando el agua de un río permanente que corría a la orilla de su barrio. De acuerdo con los testimonios de los indígenas, encontrados en el juicio seguido con la hacienda La Quemada, ${ }^{12}$ el pueblo se fundó en las tierras que se arrendaban a Don Pedro Calderón, dueño de la hacienda Buenavista. Debido a que el arrendatario tenía una labor de trigo en El Cuidado, los indígenas de Tlalcosagua se trasladaron a una legua y media al sur para refundar su pueblo con quince familias, más las que se iban agregando. Solicitaron a las autoridades medida y títulos para su pueblo con el fin de evitar conflictos y pagaron los gastos necesarios, aunque quedaron sujetos a la cabecera de Huejúcar y el título se les otorgó en la ciudad de Compostela el 8 de octubre de 1577.13 Las fechas indicadas por los indígenas no son fiables pues desde mayo de 1560 Guadalajara era la capital de la Nueva Galicia (Álvarez, 2016: 183), por lo que el título no pudo haber sido expedido en Compostela.

En este caso la fabricación de títulos, de documentos avalados por el rey para demostrar su posesión de tierras es un proceso interesante que muestra los recursos utilizados en la defensa de tierras y la utilización de la legislación para cumplir su cometido, es un recurso para otorgar veracidad a la posesión de tierras. Es un medio utilizado a partir de que la hacienda El Cuidado mandó medir sus tierras, en 1703. Incluso, los indígenas recurrieron a otro argumento para recuperar o conservar sus tierras, me refiero a destacar el servicio que como indígenas habían otorgado a la Corona participando en las pacificaciones contra «los pueblos enemigos innumerables veces sublevados», sirvieron a la causa «con armas y caballos cuando fue necesario». Recordaban en particular la sublevación de 21 pueblos acaecida en 1705, que por sus circunstancias preocupó al virrey Duque de Albuquerque, sin embargo, los auxilios de los naturales de Huejúcar, Tlalcosagua y otros pueblos mantuvieron a raya a los sublevados. De ahí que se declararan no simplemente fronterizos, «sino fronterizos útiles y necesarios para contener la bárbara insolencia de los infieles enemigos» y excelentes militares.

La memoria histórica, en este caso, se nutre de la historia oral, de recuerdos y de títulos de tierras creados ex profeso. Para los indígenas de Huejúcar y Tlalcosagua el recuerdo de ser descendientes de tlaxcaltecas, y en

\footnotetext{
${ }^{9}$ BPEJ, ARA, Ramo Civil, Caja 143, exp. 16, progresivo 1575, 1792-1798, fj. 2 f.

${ }^{10}$ BPEJ, ARA, Ramo Civil, Caja 173, exp. 2, progresivo 1932, 1788-1798, fj. 4f.

11 BPEJ, ARA, Ramo Civil, Caja 379, exp. 16, progresivo 5823, fs. 21v-22f.

${ }^{12}$ El juicio puede rastrearse en los siguientes expedientes encontrados en la BPEJ, ARA, Ramo civil: caja 232, exp. 12, progresivo 3037; caja 173, exp. 2, progresivo 1932; caja 238, exp. 13, progresivo 3156; caja 199, exp. 17, progresivo 2447.

${ }^{13}$ BPEJ, ARA, Ramo Civil, Caja 160, exp. 12, progresivo 1756, fs. 23v-26f.
} 
particular de ser indígenas de frontera, tenía una carga simbólica significativa, capaz de crear la experiencia tlaxcalteca para valorar el pasado frente al futuro.

Por su parte, los abogados de la hacienda El Cuidado argumentaban que si los naturales tenían títulos desde 1562 por qué no reclamaron las tierras que le fueron otorgadas a de la Torre. El origen de la posesión de las tierras en disputa, de acuerdo con los hacendados, se remontaba a 1562 cuando se otorgó un sitio y una caballería a nombre de López Cisneros, en donde sembró y construyó casas. Incluso presentaron la merced dada a Simón de Coca en $1561^{14}$ de dos caballerías con riego. Mientras que el pueblo de Huejúcar poseía solamente una legua por cada viento desde 1668 cuando Diego de la Torre midió las tierras y no hubo reclamos. ${ }^{15}$ Asimismo, convencidos, los hacendados, de la nulidad de los títulos presentados por los indígenas, señalaron que registraron todos los libros de mercedes, indios y decretos de 1562 y no estaba asentado, en ninguno de ellos, algún título a su favor. Además, en 1562 no era virrey Gaspar de Zúñiga, conde de Monterrey, éste comenzó a gobernar el 5 de noviembre de 1595, 33 años después de la fecha en que expidió el supuesto título. Por ello estaban convencidos de la falsedad de los títulos. ${ }^{16}$ No obstante la falsedad de los títulos, este puede ser considerado un recurso importante para defender lo amenazado.

Los indígenas utilizaron los recursos legales disponibles para defenderse y colectivamente abogaron por el respeto a los derechos otorgados desde 1591. Para recordar sus orígenes y proteger sus tierras improvisaron los títulos de la fundación de sus pueblos, su falsedad es notoria en varios aspectos: a) no era virrey en ese momento quien aseguran les expidió el título; b) todavía no se formaba el gobierno de las Fronteras de Colotlán; c) en 1562 Compostela no era capital de la Nueva Galicia. En vista de lo anterior recurrir a la historia de la fundación del pueblo, incluso a un pasado falso para crear o reforzar sus derechos era menester en la defensa, legitimación y cohesión del pueblo.

El relato, con guiños legales, indígenas, paternalistas, revela el tipo de historia que se construye. La historia oral se convierte en un objeto legal necesario para defender las tierras, con base en los títulos primordiales. De ahí que se atribuyera, en los títulos primordiales, a Gaspar de Zúñiga como virrey, emitiendo el título en 1562. El objetivo era remontar la historia del pueblo el mayor tiempo posible, probablemente se recordaban las tierras y prebendas prometidas por Miguel Caldera en la pacificación de la región, pero esto tampoco es claro ni se menciona en el litigio aquí seguido. ${ }^{17}$ Esta profundidad histórica daba validez al acceso a la tierra. Asimismo, los testimonios, las sementeras y por supuesto, la lucha contra indios infieles o sublevados, eran argumentos vinculados con el origen fundador de estos pueblos y su adhesión a la Corona.

En lo que respecta a la defensa de los hacendados, se ha demostrado (CHEVALIER, 1985) que las mercedes otorgadas por la Corona, a los españoles, en agradecimiento por los servicios de la colonización en el siglo XVI les sirvieron para ir acaparando las tierras limítrofes con sus rebaños, invadiendo las posesiones de los vecinos, tanto de indígenas como de españoles. Entre 1664 y 1697 el rey ordenó un cálculo de las tierras acaparadas para ponerlas en venta. Así, la Corona se percató de la anexión de vastos espacios realengos o públicos por parte de los hacendados (CHEVALIER, 1985: 219). Además, los hacendados también caían en irregularidades con el fin de obtener títulos y probar sus pertenencias. Por ejemplo, hacían transacciones ilegales

\footnotetext{
14 En documento referido anteriormente los hacendados señalaron que la merced a Simón de Coca se había dado en 1568.

${ }^{15}$ BPEJ, ARA, Ramo Civil, Caja 173, exp. 2, progresivo 1932, fj. $56 \mathrm{f}$

${ }_{16}$ BPEJ, ARA, Ramo Civil, Caja 199, exp. 17, progresivo 2447, fs. $51 \mathrm{f}-51 \mathrm{v}$.

17 Güereca (2016) presenta registros documentales del siglo XVII en donde los indígenas afirmaban que se les había dado la calidad de soldados y fronterizos desde la fundación de los pueblos por Miguel Caldera, anterior a la llegada de las familias tlaxcaltecas para defender el territorio y pactar la paz. La autora duda de la veracidad de tales afirmaciones aunque asegura que Caldera pactó la paz en la región hacia 1585.
} 
entre españoles, compraban a los indígenas sin dar noticia a las autoridades, etcétera. Por lo general se interesaban en las tierras con acceso a ríos o arroyos, como el caso aquí descrito.

Entre las comunidades indígenas aquí estudiadas la memoria histórica fue la principal arma para ganar terrenos. El orgullo construido alrededor de su descendencia de los tlaxcaltecas y la defensa del territorio frente a los ataques de otros grupos indígenas constituyó el principal baluarte para protegerse. Aunque en los documentos referidos no prueban si eran mestizos descendientes de tlaxcaltecas, vale la pena señalar cómo sentaron las bases para luchar por el control de la tierra. Su relato histórico fue construido a partir de la identidad y los beneficios económicos, de guerra y legales que conllevaba ser descendiente de tlaxcalteca, al servicio de la Corona. La articulación de argumentos legales e identitarios se encuentra a lo largo del proceso de defensa de los pueblos, en particular a finales del siglo XVIII, cuando hubo mayor presión por la tierra debido a que la composición étnica de la población del gobierno de las Fronteras de Colotlán incluía diversidad de castas, gracias a la movilidad de la población y a la búsqueda de los privilegios que acarreaba ser indio de frontera. Además, la migración masiva de mestizos, negros, mulatos, etcétera, a los distintos puntos del gobierno de las Fronteras de Colotlán, corrompía a los colotlecos, según palabras de las autoridades y los hacendados. El aumento de la población generó mayor presión por la tierra y el aumento de los litigios por probar la posesión.

\section{La memoria en la defensa de la tierra}

Los indígenas de Huejúcar y Tlalcosagua se unieron para hacer frente común en contra de los hacendados. Así, construyeron una estrategia basada en la memoria histórica, para lo cual recurrieron a sus títulos primordiales de 1577, entregados por la autoridad de Tlaltenango y añadieron el dictamen del alcalde mayor de Fresnillo el cual sentenciaba que debían gozar de una extensión mayor ya que la impuesta no era suficiente para las necesidades de sus habitantes. El alcalde de Fresnillo no negaba que los pueblos debían tener media legua por cada viento conforme a la ley, pero siempre y cuando fueran tierras útiles y no cuando su aspereza fuera como las de Tlalcosagua, por dos vientos, e incapaces de labrarse, en dicho caso deberían reemplazarse sin perjudicarse a terceros. ${ }^{18}$

Por lo tanto, la Real Audiencia mandó al alcalde mayor, Negrón, a medir las tierras y se les otorgó una legua por el norte, la cual gozaron hasta 1703, cuando los dueños de la hacienda El Cuidado pidieron medir sus tierras y encontraron algunas realengas, que a decir de los de Tlalcosagua eran suyas pero no pudieron defender debido a la falta de título, por lo que Tlalcosagua perdió media legua por el sur. ${ }^{19}$ Algunos meses después de la pérdida de media legua la comunidad aseguraba haber encontrado sus títulos y pidió la restitución, de acuerdo con «la disposición de la ley 9, 7 y 18 del libro $4^{\circ}$, título 12 , de nuestro municipal derecho que indistintamente previenen que no se den tierras en perjuicio de los indios y que las dadas en su agrado se les restituyan, previniéndose igualmente en la ley 8 y 9 , del libro $6^{\circ}$, título $3^{\circ}$ del mismo derecho, que a los naturales se den tierras y se conserven las que hubieren tenido.» ${ }^{20} \mathrm{El}$ abogado de los pueblos citaba las leyes para defender las tierras, en particular aquellas que indicaban que en las composiciones a españoles, así como en la venta y compra no se deberían tomar las de los indígenas. Asimismo, no dudaba en subrayar la importancia de los indios fronterizos en la defensa del territorio frente a otras castas, de lo contrario, aquellos parajes «además de llenarse de

\footnotetext{
18 Aparentemente los indígenas de Tlalcosagua solamente tenían, a principios de siglo XVIII, media legua de tierra por cada viento, pues ellos mismos pidieron extender sus medidas hacia el sur, porque en Santa María había abundantes tierras y en esa dirección quedaron con una legua, pero con media en el resto de los puntos cardinales (BPEJ, ARA, Ramo Civil, Caja 199, exp. 17, progresivo 2447, fj. 3f.).

${ }^{19}$ BPEJ, ARA, Ramo Civil, Caja 232, exp. 12, progresivo 3037.

${ }^{20}$ AHJ, Tierras y Aguas, $2^{\text {a }}$ col., vol. 114, legajo 31, exp. 3.
} 
enemigos» trastocarían el orden temporal y espiritual. En cuanto a la libertad de tributos y el fuero que gozaban, señalaba que deberían preservarse ya que los colotlecos disgustados podrían unirse con los nayaritas y tarahumaras y actuar en contra del gobierno, llegando a formar alrededor de tres mil indios armados y unos siete mil desarmados, por lo cual no se debería alterar la situación de indios fronterizos. En este sentido, la defensa no era sólo de las tierras, sino de la libertad de fuero, de conservar los privilegios de indios fronterizos y subrayar su importancia como protectores de los intereses de la Corona. El abogado mencionaba que «importa más atender a la conservación de lo que se conquista que al corto interés del erario en la exacción de tributos, además de otras consideraciones políticas de atraer por este medio a los indios inmediatos y evitar prudentemente empezar una guerra con tanto expendio de caudal y pérdida de hombres». ${ }^{21}$ Por estos motivos se pedía la restitución de las tierras, para evitar la decadencia económica de las comunidades y orillarlos a tomar otras medidas para su sustento, subrayando la necesidad de continuar resguardando la frontera y mantener el control y la paz del territorio.

Este conflicto llegó a su cúspide en el último cuarto del siglo XVIII, cuando se pusieron en marcha las reformas borbónicas. La Corona buscaba recaudar mayores recursos, por lo cual se enviaron visitadores al gobierno de las Fronteras de Colotlán para reformar el territorio, quitar las prerrogativas a los colotlecos y recolectar impuestos. En vista de los alegatos entre hacendados e indígenas por las tierras, el virrey en turno envió, en 1788, al gobernador de las Fronteras de Colotlán, Simón de Herrera, a administrar justicia en el conflicto sobre los límites de tierras, incluso señaló que debía tomar en cuenta el fuero militar que gozaban los moradores de las Fronteras de Colotlán en las causas civiles y criminales. ${ }^{22}$ El 28 de febrero de 1792, Simón de Herrera indicó que la obra pía no justificaba el avance ante las tierras de los naturales, que correspondían a Huejúcar y Tlalcosagua, por lo tanto debían ser reintegradas conforme a sus títulos. ${ }^{23} \mathrm{~A}$ pesar de la sentencia dictada a favor de las comunidades, el administrador de las haciendas apeló en mayo de 1792. Aparentemente, antes del fallo a favor de las comunidades, éstas no gozaron de las tierras, la hacienda estaba en poder de las mismas y continuó labrándolas. A razón del recurso de apelación interpuesto por la hacienda, los indígenas acudieron a su defensor para ponerlo al tanto de la situación pues carecían de tierras y consideraban que con sembrar lo que les correspondía, en tiempo oportuno, tendrían «una mediana subsistencia para la manutención de sus pobres familias». Además, los gastos que habían erogado para el caso eran considerables y el problema seguía sin resolverse. ${ }^{24}$

$\mathrm{Al}$ inicio del litigio la defensa de los indígenas no realizó interrogatorio a testigos como sí hizo la obra pía, sino que utilizó el interrogatorio de la hacienda para analizar el dicho de los declarantes. De trece testigos, seis eran arrendatarios de la obra pía y beneficiarios de las tierras en litigio. Por lo tanto, el defensor de las comunidades solamente rescató las declaraciones de siete testigos. Así, en las preguntas sobre medidas los testigos reconocieron que la Ciénega (que la hacienda tenía sembrada de trigo y era el sitio en disputa) quedaba dentro de la medida del pueblo y los indígenas estaban en posesión de ella. En cuanto a las dimensiones y límites de las tierras de las comunidades los testigos dijeron que por el oriente las tierras no estaban medidas y no se habían extendido a las tierras de los hacendados, pero por el hecho de no estar medidas no podía conocerse la invasión de alguna de las partes. En general, en todas las preguntas los testigos manifestaron el agravio

\footnotetext{
${ }^{21}$ Todos los comentarios del abogado citados en este párrafo fueron encontrados en : BPEJ, ARA, Ramo Civil, Caja 173, exp. 2, progresivo 1932, fj. $13 \mathrm{f}$.

22 BPEJ, ARA, Ramo Civil, Caja 173, exp. 2, progresivo 1932, fj. 3v.

${ }^{23}$ Ibíd., fs. $146 \mathrm{v}-147 \mathrm{f}$.

${ }^{24}$ BPEJ, ARA, Ramo Civil, Caja 143, exp. 16, progresivo 1575, fs. $11 \mathrm{f}-11 \mathrm{v}$.
} 
a los indígenas. A pesar de que la obra pía expresó tener títulos anteriores a los de los pueblos, no los había mostrado, el único documento presentado era la medida practicada por Antonio Salazar, a petición del capitán Diego de la Torre en 1668, pero este documento representaba para las comunidades la prueba de que poseían una legua por cada viento. Además, agregaba el abogado de los indígenas, en asuntos de tierras no era necesario contar con títulos, siempre y cuando la posesión del sitio excediera el medio siglo, según lo expresaba el capítulo $4^{\circ}$ de la real cédula instructiva. Por ende, deducía que las tierras en disputa pertenecían a Huejúcar y Tlalcosagua, además de aquellas que se les habían otorgado en 1562 y 1567 a través de una merced. ${ }^{25}$

A pesar de que la defensa de las comunidades utilizó los testimonios de los testigos de los hacendados a su favor, asimismo ordenó un nuevo interrogatorio con diferentes declarantes. Entre las preguntas se incluía dar información sobre el conocimiento del litigio, si sabían las medidas de los sitios en disputa y sus linderos, si era de su conocimiento que las comunidades habían perdido sus títulos, si les constaba que las tierras del pueblo eran fragosas e infructuosas a excepción de la ciénega en litigio, entre otras. ${ }^{26}$

Los testigos eran españoles e indígenas, y todos se manifestaron a favor del pueblo de Tlalcosagua. El resultado fue emitir una resolución en apoyo a los indígenas, sin embargo, en 1802 no les habían restituido sus tierras, por lo que acudieron al virrey a través de una misiva para pedir que fueran respetados sus títulos, haciendo valer el derecho que los amparaba como menores por ser indios y por lo tanto dignos de protección. Además, aseguraban que sus títulos estaban en manos de la hacienda y los pedían porque de lo contrario no podían defender lo suyo. ${ }^{27}$

A lo anterior añadían que la población aumentaba constantemente y por ende necesitarían más tierras. En 1802 el pueblo se componía de 600 hombres casados, más las mujeres, niños y viejos, por lo tanto rebasaba las 1500 personas. Robert Shadow (1986) con base en los libros de bautismos asegura el sostenido crecimiento de Huejúcar en los quinquenios 1766-1770, 1776-1780, 1796-1800 y 1806-1810. Además, asevera que Huejúcar y Santa María constituían las poblaciones con más indígenas del gobierno colotleco y Huejúcar tenía aproximadamente la misma extensión que Colotlán (SHADOW, 1986: 68-70).

Debido al crecimiento de la población, los indígenas pedían la medida de sus tierras, la revisión de las invasiones de las haciendas vecinas y algunos ranchos, el amojonamiento conforme a sus títulos y agregar las tierras que hubiera realengas, para lo cual estaban dispuestos a pagar el precio en el que fueran valuadas. En septiembre de 1802 se realizaron las medidas y se les otorgaron dos sitios de ganado mayor por razón de fundo legal y media legua más por cada viento. ${ }^{28}$ Incluso, la comunidad, con el gobernador y alcalde al frente, se autodenominaron indios guerreros y fronterizos, con tierras adquiridas por sus antepasados, que «desde tiempos inmemoriales les correspondían como fundo» y por lo tanto pedían el respeto y restitución de esas heredades. ${ }^{29}$ En consecuencia, el defensor demandó las tierras que correspondían al pueblo de acuerdo con la real provisión de 18 de junio de 1577.

Este litigio constituyó una lucha colectiva en la cual se dejaron de lado las diferencias entre los miembros de los pueblos de Tlalcosagua y Huejúcar, incluso participaron en su defensa vecinos españoles. Asimismo, recuperaron y resaltaron un pasado común con un presente vivo: ser indios fronterizos, descendientes de tlaxcaltecas. Se reforzó el pasado para enfrentar a los hacendados y a algunas autoridades locales. Esa conciencia y

\footnotetext{
${ }^{25}$ BPEJ, ARA, Ramo Civil, Caja 173, exp. 2, progresivo 1932, fs. 110f-135v.

26 BPEJ, ARA, Ramo Civil, Caja 232, exp. 12, progresivo 3037, fs. 45f-45v.

${ }^{27}$ BPEJ, ARA, Ramo Civil, Caja 218, exp. 28, progresivo 2800, fs. 1v-3f.

${ }^{28}$ BPEJ, ARA, Ramo Civil, Caja 379, exp. 16, progresivo 5823, fs. 20f-21f.

${ }^{29}$ AHJ, Tierras y aguas, $2^{\text {a }}$ col., vol. 114, legajo 31, exp. 3.
} 
cohesión se construyó con base en argumentos legales. El relato histórico se creó vinculado con el aparato legal colonial promovido por la Corona española. Además, la defensa descansaba en los privilegios concedidos a los tlaxcaltecas en la colonización y pacificación de la frontera colotleca, y en su lucha contra los sublevados chichimecas (término genérico). En los albores del siglo XIX los indígenas no dudaban en denominarse descendientes de tlaxcaltecas, por ende guardianes de la frontera y detentores de los privilegios ganados en el siglo XVI. A pesar de la sentencia a favor de los indígenas, los hacendados refrendaron su poderío económico y político al no desocupar las tierras.

Poniendo de lado los resultados del litigio, el análisis revela la capacidad de los indígenas por apelar al pasado en la defensa de sus heredades. La memoria tiene que ser significativa sino pierde su fuerza comunicadora, quizá por esta razón se habla del pasado tlaxcalteca y de su calidad como indios de frontera en momentos clave (APFELBAUM, 2010: 87). La memoria relata, evoca el significado que los grupos dan a su pasado, desde el presente.

\section{Fuentes}

Biblioteca Pública del Estado de Jalisco (BPEJ), Archivo de la Real Audiencia (ARA) Archivo Histórico de Jalisco (AHJ), Libros de Tierras y Aguas

\section{REFERENCIAS BIBLIOGRÁFICAS}

ÁLVAREZ, S. «La primera regionalización (1530-1570)». En CALVO, T. y REGALADO, A. (coords.). (2016). Historia del Reino de la Nueva Galicia. Guadalajara: Universidad de Guadalajara, pp. 165-210.

APFELBAUM, E.(2010). «Halbwachs and the social properties of memory» en RADSTONE, S. y SCHWARZ, B. (eds.). (2010). Memory. Histories, theories, debates. Nueva York: Fordham University, pp. 77-92.

ARLEGUI, J. (1851). Crónica de la provincia de N.S.P.S. Francisco de Zacatecas. México: Cumplido, calle de los rebeldes $n .^{\circ} 2$.

ARREGUI, D. (1980). Descripción de la Nueva Galicia. México: UNED.

BAZANT, J. (1980). Cinco haciendas mexicanas. Tres siglos de vida rural en San Luis Potosi (1600-1910). México: El Colegio de México.

BERTHE, J., CALVO, T. y JIMÉNEZ PELAYO, Á. (2000). Sociedades en construcción. México: Universidad de Guadalajara, Centre Français d'Ètudes Mexicaines et Centraméricaines.

BOOTH, J. (1999). «Communities of memory: on identity, memory and debt». The American Political Science Review 93 (2), pp. 249-263.

CHEVALIER, F. (1985). La formación de los latifundios en México. México: FCE.

ENGLUND, S. (1992). «The ghost of nation past». The Journal of Modern History 64 (2), pp. 299-320.

FERNÁNDEZ, R. y ROMÁN, J. «Presencia tlaxcalteca en Nueva Galicia». En CAVAZOS GARZA, I., et. al. (1999). Constructores de la nación. La migración tlaxcalteca en el Norte de la Nueva España. México: El Colegio de San Luis, Gobierno del Estado de Tlaxcala, pp. 17-34.

GÜERECA DURÁN, R. (2016). «Las milicias tlaxcaltecas en Saltillo y Colotlán». Estudios de Historia Novohispana 54, pp. $50-73$. 
MOTA Y ESCOBAR, A. (1940). Descripción geográfica de los reynos de Nueva Galicia, Nueva Vizcaya y Nuevo León. México: editorial Pedro Robredo.

MURIÁ, J. M. (1997). Los límites de Jalisco. Zapopan: El Colegio de Jalisco.

NORA, P. (2008). Les lieux de la mémoire. Montevideo: ediciones Trilce.

ROBINSON, B. (2016). The mark of rebels: indios fronterizos and mexican independence. Tuscaloosa, Alabama: The University of Alabama Press.

SEGO, E. (1998). Aliados y adversarios: los colonos tlaxcaltecas en la frontera septentrional de Nueva España. México: El Colegio de San Luis.

SHADOW, R. (1986). «La frontera norteña de la Nueva Galicia: las parroquias de Colotlán, 1725-1820». Relaciones 25 , pp. $45-75$.

VELÁZQUEZ, M. (1961). Colotlán: doble frontera contra los bárbaros. México: UNAM. 